Article

\title{
Modeling and Enhanced Error-Free Current Control Strategy for Inverter with Virtual Resistor Damping
}

\author{
Cheng Nie ${ }^{1,2}$, Yue Wang ${ }^{1,2}$, Wanjun Lei ${ }^{1,2, *}$, Tian $\mathrm{Li}^{2}$ and Shiyuan Yin ${ }^{2}$ \\ 1 State Key Laboratory of Electrical Insulation and Power Equipment, Xi'an Jiaotong University, Xi'an 710049, \\ China; niecheng@stu.xjtu.edu.cn (C.N.); yuewang@mail.xjtu.edu.cn (Y.W.) \\ 2 Key Laboratory of Shaanxi Smart Grid, Xi'an Jiaotong University, Xi'an 710049, China; \\ litian3117306094@stu.xjtu.edu.cn (T.L.); 12291162@bjtu.edu.cn (S.Y.) \\ * Correspondence: leiwanjun@xjtu.edu.cn; Tel.: +86-29-8266-8666
}

Received: 31 July 2018; Accepted: 17 September 2018; Published: 20 September 2018

\begin{abstract}
In microgrid, the grid-connected inverter current with the LCL (inductor-capacitor-inductor) output filter is amplified at certain frequencies. Using virtual resistor damping method can help suppress the amplification. By choosing an appropriate virtual resistor value, the model of the inverter current control loop is simplified as a $2^{\text {nd }}$-order lowpass filter. Based on such simplified model, this paper proposes a design method of reference current compensation controller, which does not require decomposition of harmonic components. With the reference compensation, the inverter output current control precision is improved obviously. The simulation and experimental results verify the accuracy of the inverter simplified model and effectiveness of the reference compensation design method.
\end{abstract}

Keywords: microgrid; power quality control; optimal virtual resistor; $2^{\text {nd }}$-order lowpass filter; reference current compensation

\section{Introduction}

With the increasing concerns of traditional energy shortage, greenhouse gas emissions, environmental pollution problem and so on, applications of microgrid become popular [1,2]. The typical microgrid system contains traditional power grid and DG (Distributed Generation) system [3-5]. The technology of DG system has been developed rapidly [6,7]. A lot of research results show that the DG inverter has the power quality control ability [8,9], such as being used to compensate load harmonic current $[10,11]$. For harmonic current compensation, the output harmonic current control performance directly affects the harmonic current compensation effect of DG inverter.

In microgrid, the inverter needs an effective filter [12,13] to avoid switching and multiple-switching frequency harmonics [14]. Compared with the L filter, the LCL filter is a more attractive solution [15,16]. However, because the potential resonance problem [17-20], precise current control of inverter with LCL filter is difficult in practical application.

The resonance problem can be solved by active damping method. In general, active damping is realized by introducing one more feedforward variable into the control loop [21]. There are mainly two situations. First, for grid-side current control, feeding back converter-side current [22] or capacitor current [23,24] can both achieve good damping effect. In [22], the current control loop is double-loop structure. The outer loop controls the output current and the inner loop stabilizes the system. In [23,24], the feeding back capacitor current is used to generate an additional current reference. This is equivalent to adding a resistor to the mathematical model. They only focus on the control of fundamental component. The harmonic component control with virtual resistor damping is not analyzed [25-28]. Second, for inverter-side current control, capacitor voltage contributes to stabilize the system [29-31]. 
In [30], dead-beat control is used as current controller and the capacitor harmonic voltage is introduced into the current control loop through a proportional controller, suppressing resonance effectively. But the control target is only the output fundamental current, the effect on the output harmonic current control is also not analyzed. In [31], based on NORTON's equivalence circuit, the effect of virtual resistance on the inverter output harmonic current amplitude is studied. The output harmonic current phase delay is compensated by closed-loop control of filter capacitor harmonic voltage phase. Although the output harmonic current is controlled, the out harmonic current phase is not sampled and the capacitor voltage phases of each harmonics are extracted separately. The compensation is indirect and discrete.

The purpose of this paper is to propose a simple control method to improve the effect of inverter harmonic current control. Firstly, the equivalent current source model of inverter with virtual resistor is established. Secondly, the paper has analyzed the relationship between virtual resistor value and inverter harmonic current control character. The model of the inverter current control loop can be simplified as $2^{\text {nd }}$-order lowpass filter by choosing appropriate resistor value, which can be obtained according to the quality factor regulation of the simplified model. Thirdly, the phase lag angle of inverter output harmonic current and the harmonic compensation error are analyzed quantitatively. Then the design method of reference compensation controller is proposed based on the simplified model. And then, the paper discusses the influence of LCL parameters on reference compensation control. Finally, the simulation and experimental results show the correctness of the simplified model and the effectiveness of the reference compensation.

\section{Modelling of the Inverter with Virtual Resistor Control}

The configuration of system with grid-connected distributed inverter of the microgrid is shown in the Figure 1. There is power grid, PV and its inverter. They provide electricity to the load together.

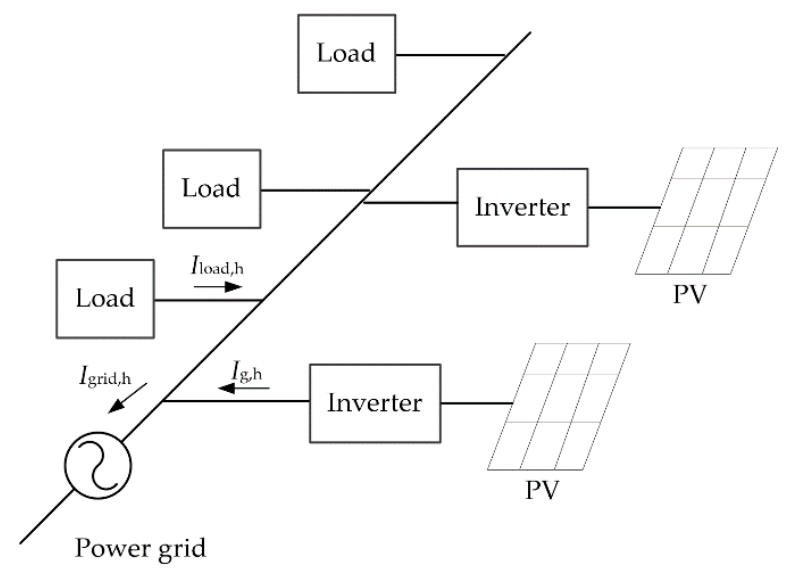

Figure 1. Circuit diagram of microgrid.

In the microgrid system, except providing fundamental energy, distributed inverter can also output harmonic current $I_{\mathrm{g}, \mathrm{h}}$ to compensate the load harmonic current $I_{\text {load, }}$. There are already lots of research on the distributed inverter control and mainly focus on fundamental component [32-34]. In this section, harmonic current control model of the inverter with virtual resistor damping is established.

The schematic diagram of distributed inverter is presented in Figure 2, the upper part is the main circuit configuration and the lower part is the digital control diagram. $L_{1}$ is the converter-side filter inductance and $L_{2}$ is the grid-side filter inductance, $C_{\mathrm{f}}$ is the filter capacitor.

The current control method here is based on the traditional proportional control method. Converter side current $I_{\mathrm{L}}$ is selected as the controlled object and filter capacitor voltage $V_{\mathrm{C}}$ is measured 
for system synchronization and active damping, in this way only two feedback sensors are needed. The inverter output voltage is expressed as Equation (1):

$$
V_{\mathrm{PWM}}(s)=V_{\mathrm{C}}(s)+K_{\mathrm{p}}\left(I_{\text {ref }}(s)-I_{\mathrm{VD}}(s)-I_{\mathrm{L}}(s)\right)
$$

Here $I_{\text {ref }}(s)$ and $I_{\mathrm{L}}(s)$ are the reference current and the measured converter-side feedback current, respectively. $K_{\mathrm{p}}$ is a parameter of current controller, equals to a constant value. $V_{\mathrm{c}}(s)$ is the measured capacitor voltage, used to compensate the disturbance of ac side voltage. $I_{\mathrm{VD}}(s)$ is the damping current, which is generated by capacitor harmonic voltage, as shown in Equation (2).

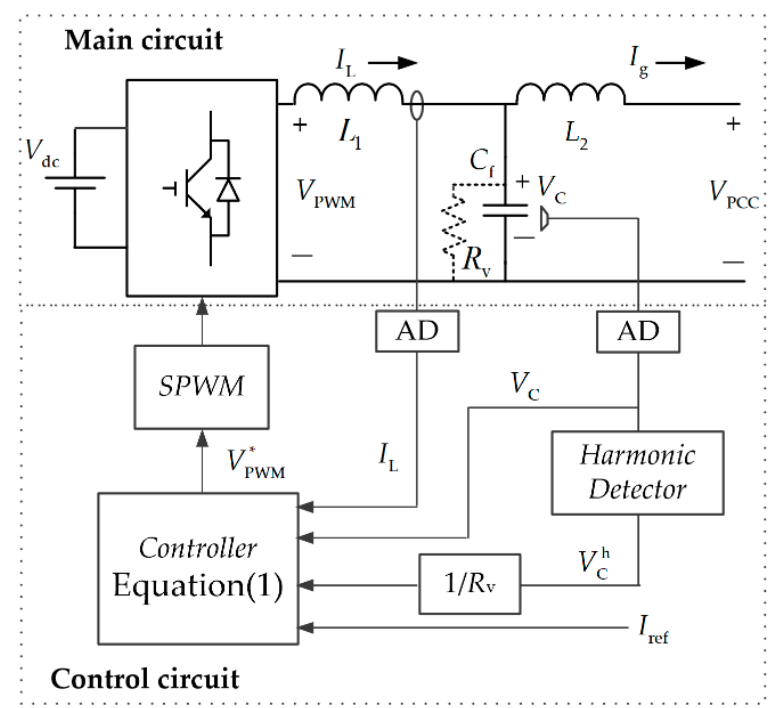

Figure 2. Conventional proportion-controlled DG system with virtual damping.

$$
I_{\mathrm{VD}}(s)=\frac{V_{\mathrm{C}}(s)}{R_{\mathrm{V}}}
$$

In the Equation (2), $R_{\mathrm{V}}$ is a constant value with the unit ohms, equals to the virtual resistor's value. In this way, the virtual resistor is parallel connect with the filter capacitor, as in Figure 2. Based on the open-loop transfer function of LCL network, Equations (3)-(5), the relationship between the output current $I_{\mathrm{g}}(s)$ and the reference current $I_{\text {ref }}(s)$ of the inverter can be obtained, as Equation (6):

$$
\begin{gathered}
I_{\mathrm{L}}(s)=H_{1}(s) V_{\mathrm{PWM}}(s)+H_{2}(s) V_{\mathrm{PCC}}(s) \\
I_{\mathrm{g}}(s)=H_{3}(s) V_{\mathrm{PWM}}(s)+H_{4}(s) V_{\mathrm{PCC}}(s) \\
V_{\mathrm{C}}(s)=H_{5}(s) V_{\mathrm{PWM}}(s)+H_{6}(s) V_{\mathrm{PCC}}(s)
\end{gathered}
$$

The coefficients $H_{1}(s)-H_{6}(s)$ are determined by LCL filter parameters and are shown at the end of this section.

$$
I_{\mathrm{g}}(s)=G_{\mathrm{T}}^{\mathrm{ad}}(s) I_{\mathrm{ref}}(s)-Y_{\mathrm{eq}}^{\mathrm{ad}}(s) V_{\mathrm{PCC}}(s)
$$

The coefficients $G_{\mathrm{T}}^{\mathrm{ad}}(s)$ and $-Y_{\mathrm{eq}}^{\mathrm{ad}}(s)$ describe the output current responses to the current reference and the PCC voltage, respectively. The detailed expressions are described as follows:

$$
G_{\mathrm{T}}^{\mathrm{ad}}(s)=\frac{K_{\mathrm{p}} H_{3}(s)}{1-H_{5}(s)\left(1-\frac{K_{\mathrm{p}}}{R_{\mathrm{v}}}\right)+K_{\mathrm{p}} H_{1}(s)}
$$




$$
Y_{\mathrm{eq}}^{\mathrm{ad}}(s)=\frac{K_{\mathrm{p}} H_{2}(s) H_{3}(s)-H_{3}(s) H_{6}(s)\left(1-\frac{K_{\mathrm{p}}}{R_{\mathrm{v}}}\right)}{1-H_{5}(s)\left(1-\frac{K_{\mathrm{p}}}{R_{\mathrm{v}}}\right)+K_{\mathrm{p}} H_{1}(s)}-H_{4}(s)
$$

Figure 3 describes the corresponding Norton's equivalent circuit of the inverter. $G_{\mathrm{T}}^{\text {ad }}(s)$ behaves as the coefficient of current source and $Y_{\mathrm{eq}}^{\mathrm{ad}}(s)$ represents as the associated parallel admittance.

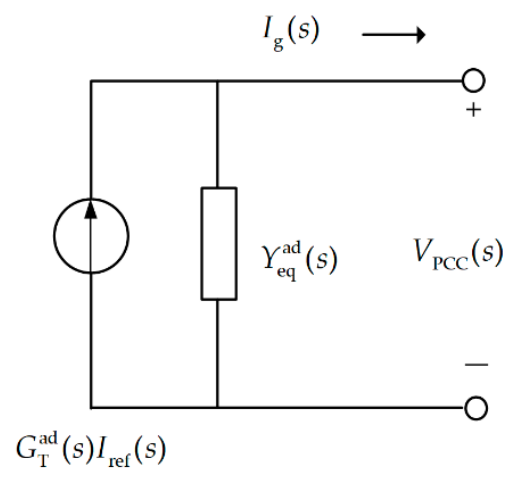

Figure 3. Equivalent current source model of the inverter.

$$
\begin{aligned}
& H_{1}(s)=\frac{L_{2} C_{\mathrm{f}} s^{2}+1}{L_{1} L_{2} C_{\mathrm{f}} s^{3}+\left(L_{1}+L_{2}\right) s} \\
& H_{2}(s)=-\frac{1}{L_{1} L_{2} C_{\mathrm{f}} s^{3}+\left(L_{1}+L_{2}\right) s} \\
& H_{3}(s)=\frac{1}{L_{1} L_{2} C_{\mathrm{f}} s^{3}+\left(L_{1}+L_{2}\right) s} \\
& H_{4}(s)=-\frac{L_{1} C_{\mathrm{f}} s+1}{L_{1} L_{2} C_{\mathrm{f}} s^{3}+\left(L_{1}+L_{2}\right) s} \\
& H_{5}(s)=\frac{L_{2} s}{L_{1} L_{2} C_{\mathrm{f}} s^{3}+\left(L_{1}+L_{2}\right) s} \\
& H_{6}(s)=\frac{L_{1} s}{L_{1} L_{2} C_{\mathrm{f}} s^{3}+\left(L_{1}+L_{2}\right) s}
\end{aligned}
$$

\section{Optimal Virtual Resistor Value of the Inverter}

Form the Equation (7), the value of virtual resistor affects the coefficients $G_{\mathrm{T}}^{\text {ad }}(s)$. It means $R_{\mathrm{v}}$ value can regulate the harmonic current control performance. Bode plot of coefficient $G_{\mathrm{T}}^{\text {ad }}(s)$ with different $R_{\mathrm{V}}$ is shown in Figure 4. Table 1 lists the parameters of the system. 


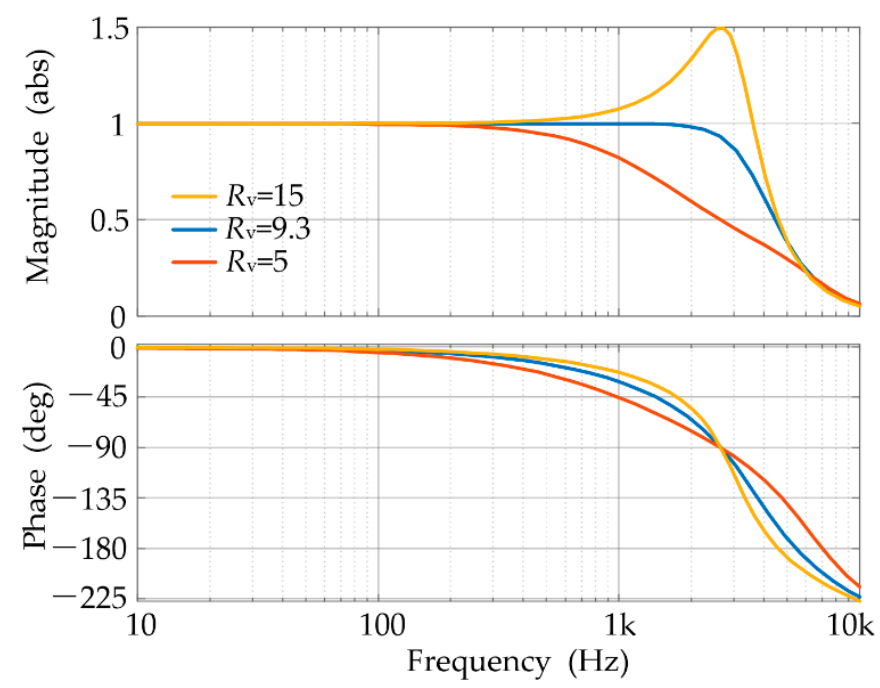

Figure 4. Bode plot of $G_{\mathrm{T}}^{\mathrm{ad}}(s)$ with different virtual resistor.

Table 1. Parameters of the System.

\begin{tabular}{cccc}
\hline Symbol & Value & Symbol & Value \\
\hline$L_{1}$ & $0.6 \mathrm{mH}$ & $V_{\mathrm{dc}}$ & $600 \mathrm{~V}$ \\
$L_{2}$ & $0.6 \mathrm{mH}$ & $V_{\text {grid }}$ & $380 \mathrm{~V}(50 \mathrm{~Hz})$ \\
$C_{\mathrm{f}}$ & $6 \mu \mathrm{F}$ & $K_{\mathrm{p}}$ & 30 \\
$L_{\text {grid }}$ & $0.1 \mathrm{mH}$ & $f_{\mathrm{s}}$ & $20 \mathrm{kHz}$ \\
\hline
\end{tabular}

From Figure 4, the $R_{\mathrm{v}}$ value has both effect on the amplitude-frequency and phase-frequency characteristics of $G_{\mathrm{T}}^{\mathrm{ad}}(s)$. From the amplitude-frequency characteristic curve, as the $R_{\mathrm{v}}$ value decreases, the curve decreases more near the resonant frequency. And there is an optimal virtual resistance value $\left(R_{\mathrm{V}}=9.3 \Omega\right)$, which can make the amplitude-frequency characteristic curve closer to unit 1 below $2 \mathrm{kHz}$. From the phase-frequency characteristic curve, all the curves cross $90^{\circ}$ at resonance frequency. Below the resonance frequency, smaller $R_{\mathrm{v}}$ value responses to more phase lag; above the resonance frequency, smaller $R_{\mathrm{v}}$ value response to less phase lag.

The coefficients $G_{\mathrm{T}}^{\text {ad }}(s)$ is 3-order s-domain function, related to the LCL parameters, current control loop $K_{\mathrm{p}}$ and virtual resistance $R_{\mathrm{v}}$, as follow:

$$
G_{\mathrm{T}}^{\mathrm{ad}}(s)=\frac{K_{\mathrm{p}}}{L_{1} L_{2} C s^{3}+K_{\mathrm{p}} L_{2} C s^{2}+\left(L_{1}+K_{\mathrm{p}} L_{2} / R_{\mathrm{v}}\right) s+K_{\mathrm{p}}}
$$

In Equation (15), the coefficient of $s^{3}$ term is $2.16 \times 10^{-12}$, and the coefficient of $s^{2}$ is $1.08 \times 10^{-7}$, which is about $10^{5}$ times of the coefficient of $s^{3}$. When the $s^{3}$ term in Equation (15) is removed, the approximate expression of $G_{\mathrm{T}}^{\text {ad }}(s)$ is obtained, as Equation (16):

$$
\hat{G}_{\mathrm{T}}^{\mathrm{ad}}(s)=\frac{1 /\left(L_{2} C_{\mathrm{f}}\right)}{s^{2}+\left(L_{1}+K_{\mathrm{p}} L_{2} / R_{\mathrm{v}}\right) /\left(K_{\mathrm{p}} L_{2} C_{\mathrm{f}}\right) s+1 /\left(L_{2} C_{\mathrm{f}}\right)}
$$

When Equation (16) is regarded as the expression of $2^{\text {nd }}$-order lowpass filter, the corresponding cutoff frequency and quality factor are respectively.

$$
\omega_{\mathrm{n}}=\sqrt{\frac{1}{L_{2} C_{\mathrm{f}}}}
$$




$$
\delta=\frac{L_{1} R_{\mathrm{v}}+K_{\mathrm{p}} L_{2}}{2 K_{\mathrm{p}} R_{\mathrm{v}}} \omega_{\mathrm{n}}
$$

According to Equation (17), the cutoff frequency is a function of the grid-side inductor $L_{2}$ and the filter capacitor $C_{\mathrm{f}}$. The quality factor is a function of the virtual resistor $R_{\mathrm{V}}$ and LCL parameters. For $2^{\text {nd }}$-order lowpass filter, when the value of quality factor is 0.707 , the amplitude-frequency characteristic curve has not overshoot. According to the parameters in Table 1, the cutoff frequency is $16,666.67 \mathrm{rad} / \mathrm{s}$, and the optimal virtual resistor values is $9.3 \Omega$.

Figure 5 shows a comparison between the transfer function $G_{\mathrm{T}}^{\text {ad }}(s)$ and the transfer function of the second order low pass filter (LPF). In Figure 5, the model of the inverter with optimal virtual resistor damping (blue line) is very similar to that of the $2^{\text {nd }}$-order lowpass filter (red line). For the amplitude-frequency characteristic, the inverter and the $2^{\text {nd }}$-order lowpass filter are basically the same below $1 \mathrm{kHz}$. Then, as the frequency increases, the attenuation of the $2^{\text {nd }}$-order lowpass filter is greater than that of the inverter. For the phase-frequency characteristic, the two models almost coincide with each other below resonant frequency.

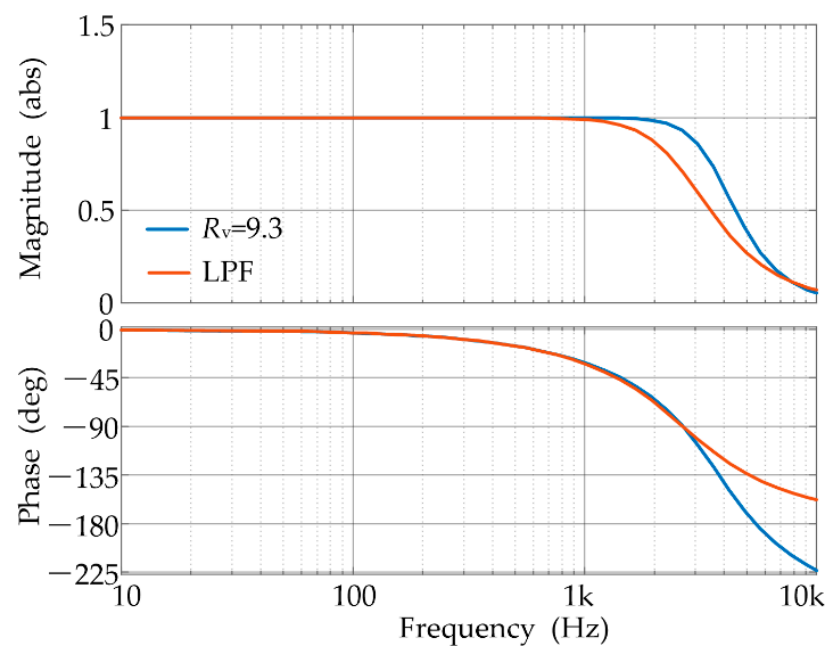

Figure 5. Comparison between the inverter and LPF.

\section{Reference Current Compensation Method}

With the optimal virtual resistor damping, the output current control performance of the inverter can be approximately a $2^{\text {nd }}$-order lowpass filtering model. Although the amplitude of the output current is almost the same as the reference current, but the phase lag problem needs be considered carefully. At the frequency $1.5 \mathrm{kHz}$, the phase lag degree is almost 45 degrees. This will affect the harmonic current compensation ability of inverter.

The relationship of current vector of system in Figure 1 is shown in Figure 6.

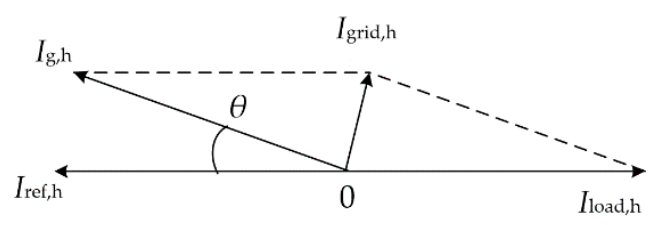

Figure 6. Diagram of current vector relationship.

In Figure $6, I_{\text {load, }}$ is the load harmonic current. Naturally, the amplitude-equal and phase-inverse vector $I_{\text {ref_h }}$ is the reference harmonic current of the inverter. As mentioned before, the output current is amplitude-equal but phase-lag, as vector $I_{\mathrm{g}, \mathrm{h}}$ in Figure 6 . The synthetic vector $I_{\text {grid,h }}$ is the grid harmonic current. The fact that $I_{\text {grid, } h}$ is not equal to zero means poor harmonic current compensation performance of the inverter. 
In order to evaluate the influence of phase lag on current control, harmonic compensation error rate $\alpha$ is defined, as shown in Equation (19).

$$
\alpha=\frac{\left|I_{\text {grid, } h}\right|}{\left|I_{\text {load,h }}\right|}
$$

In Equation (19), the numerator is the grid harmonic current, the denominator is the load harmonic current. When without any compensation, the grid harmonic current is equal to the load harmonic current, the ratio $\alpha$ is equal to unit 1 . When with compensation, the grid harmonic current is less than the load harmonic current, the ratio $\alpha$ is less than unit 1 . When the $\alpha$ is equal to 0 , means no harmonic component in the grid current, also corresponds to the best current control effect.

With optimal virtual resistor, the amplitude of the output current is the same as the reference current. Then the harmonic compensation error rate is a function of lag angle, as Equation (20):

$$
\alpha=\frac{\sqrt{\left|I_{\mathrm{g}, \mathrm{h}}\right| 2+\left|I_{\text {Load, } \mathrm{h}}\right| 2-2\left|I_{\mathrm{g}, \mathrm{h}}\right|\left|I_{\text {Load, } \mathrm{h}}\right| \cos \theta}}{\left|I_{\text {Load }, \mathrm{h}}\right|} \times 100 \%
$$

Table 2 shows the phase delay angle and compensation error rate below $\mathrm{f}<1.5 \mathrm{kHz}$. From Table 2, phase lag problem will lead to serious harmonic compensation error, especially for the high frequency harmonics. Therefore, it is necessary to compensate the phase of the reference current to reduce the current control error.

Table 2. Phase Delay and Harmonic Compensation Error.

\begin{tabular}{cccccccccc}
\hline Harmonic Order & 5th & 7th & 11th & 13th & 17th & 19th & 23th & 25th & 29th \\
\hline$\theta$ & $7.6^{\circ}$ & $10.7^{\circ}$ & $16.8^{\circ}$ & $19.9^{\circ}$ & $26.2^{\circ}$ & $29.4^{\circ}$ & $35.7^{\circ}$ & $38.9^{\circ}$ & $45.6^{\circ}$ \\
$\alpha(\%)$ & 1.2 & 2.5 & 6.0 & 8.4 & 14.5 & 18.2 & 26.6 & 31.4 & 42.5 \\
\hline
\end{tabular}

Figure 7 shows the principle of reference compensation control.

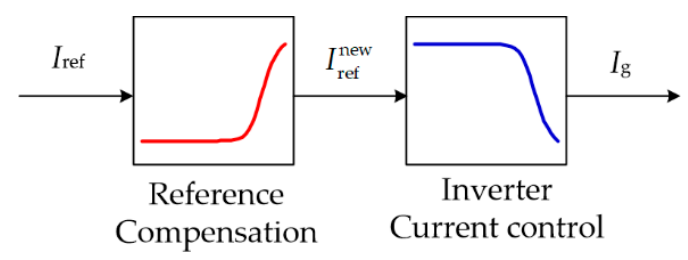

Figure 7. Schematic diagram of reference compensation.

The reference current $I_{\text {ref }}$ first goes through a regulation loop, whose function is to generate a new reference $I_{\text {ref }}^{\text {new }}$. The new reference is phase ahead of the old ones, and the leading angle increases with the frequency increase. Although the output current is still lagging the new reference $I_{\text {ref }}^{\text {new }}$, but the output current is consistent with reference current $I_{\text {ref. }}$. In this way, the phase delay of the output current is compensated.

Considering that the current control model of the inverter with optimal virtual resistor is basically agree with the $2^{\text {nd }}$-order lowpass filter in the phase-frequency characteristics. Therefore, the reference current regulation method proposed in this paper is based on the inverter's $2^{\text {nd }}$-order lowpass filtering model $G_{\mathrm{T}}^{\text {ad }}(s)$.

The reference compensation process is to divide the reference current $I_{\text {ref }}(s)$ by the inverter's $2^{\text {nd }}$-order lowpass filter model, as Equation (21).

$$
I_{\text {ref }}^{\text {new }}(s)=I_{\text {ref }}(s) \cdot \frac{1}{\hat{G}_{\mathrm{T}}^{\text {ad }}(s)}
$$


With the reference compensation, the inverter output current is:

$$
I_{\mathrm{g}}^{\mathrm{ad}}(s)=I_{\mathrm{ref}}(s) G(s)-Y_{\mathrm{eq}}^{\mathrm{ad}}(s) V_{\mathrm{PCC}}(s)
$$

Here,

$$
G(s)=G_{\mathrm{T}}^{\mathrm{ad}}(s) \cdot \frac{1}{\hat{G}_{\mathrm{T}}^{\mathrm{ad}}(s)}
$$

The characteristics of $G(s)$ determine the inverter current control character. Figure 8 is the bode plot of $G(s)$. It can be seen from the amplitude-frequency characteristic of the coefficient $G(s)$ that below $1 \mathrm{kHz}$, the curve is basically equal to unit 1 . From the phase-frequency characteristic, the phase lag problem is well compensated below $2.5 \mathrm{kHz}$. Above all, for the application of frequency $\mathrm{f}<1.5 \mathrm{kHz}$, the reference current compensation based on $2^{\text {nd }}$-order lowpass filter model has obvious effect.

The comparison results of harmonic compensation error rate without and with reference compensation method are shown in Table 3.

As can be seen from the data in Table 3, when there is no reference compensation, the error rate of harmonic compensation is large, and the compensation error rate increases with the increase of harmonic frequency. While with the reference compensation, the compensation error rate of each harmonic has been significantly reduced.

Table 3. Error of the harmonic current compensation.

\begin{tabular}{cccccccccc}
\hline \multirow{2}{*}{ Control Mode } & \multicolumn{1}{c}{$\boldsymbol{c}$ /\% } \\
\cline { 2 - 9 } & 5th & 7th & 11th & 13th & 17th & 19th & 23th & 25th & 29th \\
\hline Without reference compensation & 1.2 & 2.5 & 6.0 & 8.4 & 14.5 & 18.2 & 26.6 & 31.4 & 42.5 \\
With reference compensation & 0.1 & 0.2 & 0.4 & 0.6 & 1.3 & 1.5 & 2.6 & 3.5 & 5.6 \\
\hline
\end{tabular}

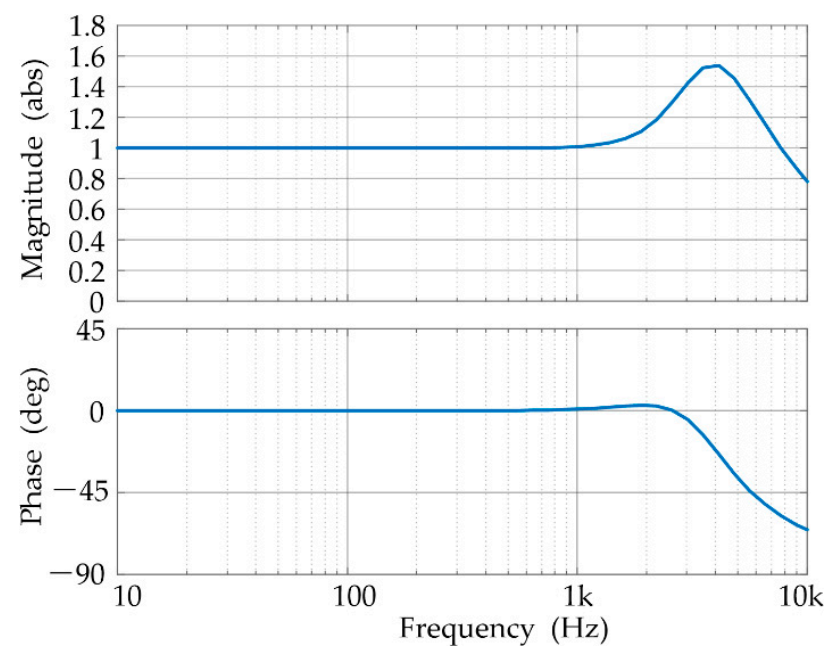

Figure 8. Bode plot of the coefficient $G(s)$.

\section{Effect of LCL Parameters on Performance of the Reference Compensation Method}

The $2^{\text {nd }}$-order lowpass filter model of the inverter ignores the three orders item of the transfer function $G_{\mathrm{T}}^{\text {ad }}(s)$ in its closed-loop model, which affects the final reference compensation effect. As can be seen from Figure 8, when the frequency is less than $1.5 \mathrm{kHz}$, the phase lags problem is well compensated. But with the frequency increasing, the amplitude frequency-characteristic of $G(s)$ has overshoot. For different LCL parameters, the effect of reference compensation control is different.

Many literatures have studied the parameter design methods of LCL filter. The LCL parameter design method is not studied in this paper. Based on the parameter design method $[33,34]$, this paper 
selects four different LCL parameters, as shown in Table 4. For each group, the grid-side inductance is equal to the inverter-side inductance. And they have the same resonance frequency.

Table 4. LCL parameters for comparison.

\begin{tabular}{ccccc}
\hline Symbol & $\boldsymbol{L}_{\mathbf{1}}=\boldsymbol{L}_{\mathbf{2}}$ & $\boldsymbol{C}_{\mathbf{f}}$ & $f_{\mathbf{r}}$ & $f_{\text {LPF }}$ \\
\hline 1 & $0.8 \mathrm{mH}$ & $4.5 \mu \mathrm{F}$ & & \\
2 & $0.6 \mathrm{mH}$ & $6 \mu \mathrm{F}$ & & \\
3 & $0.4 \mathrm{mH}$ & $9 \mu \mathrm{F}$ & $3700 \mathrm{~Hz}$ & $2653 \mathrm{~Hz}$ \\
4 & $0.2 \mathrm{mH}$ & $18 \mu \mathrm{F}$ & & \\
\hline
\end{tabular}

In Equation (24) is the resonant frequency of LCL filter.

$$
f_{\mathrm{r}}=\frac{1}{2 \pi} \sqrt{\frac{L_{1}+L_{2}}{L_{1} L_{2} C}}=\frac{1}{2 \pi} \sqrt{\frac{2}{L_{2} C}}=\sqrt{2} f_{\mathrm{LPF}}
$$

Equation (24) shows that when $L_{1}=L_{2}$ and the resonance frequency is the same, the four groups of parameters have the same $2^{\text {nd }}$-order lowpass filter model. The bode plot of $G(s)$ is shown in the Figure 9.

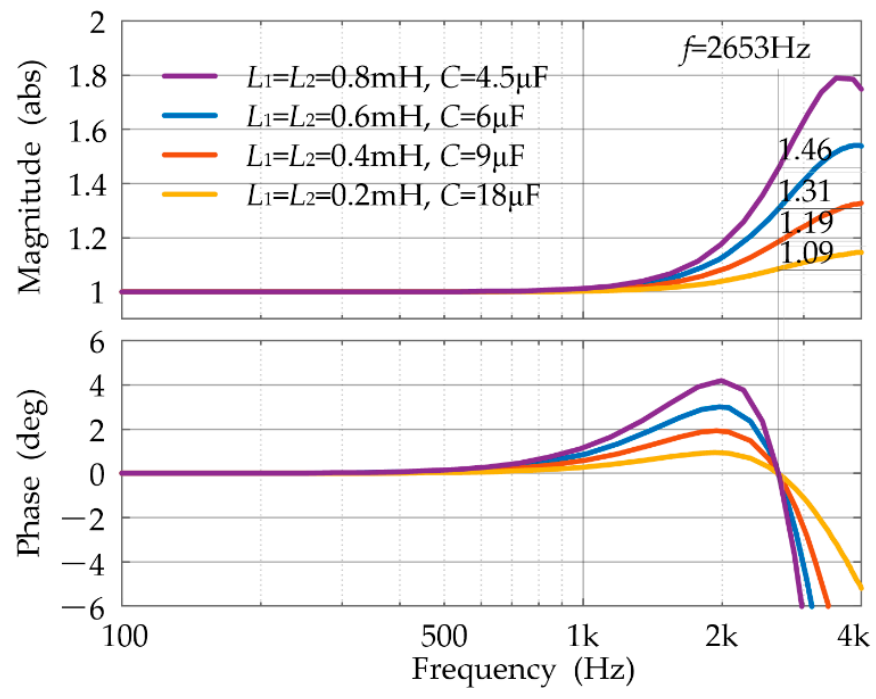

Figure 9. Bode plot of $G(s)$ with different LCL parameters.

In the Figure 9, the four phase-frequency characteristic curves crossing 0 degree at the same frequency. The simplified expression of $G(s)$ is as follows:

$$
G(s)=\frac{s^{2}+1.414 \omega_{\mathcal{c}} s+\omega_{\mathrm{c}}^{2}}{\frac{L_{1}}{K_{\mathrm{p}}} s^{3}+s^{2}+1.414 \omega_{\mathrm{c}} s+\omega_{\mathrm{c}}^{2}}
$$

The zero-cross frequency of the phase-frequency characteristic curves can be obtained by solving Equation (26).

$$
\angle|G(s)|=0^{\circ}
$$

The result is $\omega_{\mathrm{x}}=\omega_{\mathrm{LPF}}$, it is just equal to cut-off frequency of the inverter's $2^{\text {nd }}$-order lowpass filter model. And the amplitude value at this frequency is:

$$
|G(s)|=\frac{1.414}{1.414-L_{1} \omega_{\mathrm{LPF}} / K_{\mathrm{p}}}
$$


According to the above analysis, LCL parameters have the following two effects on the reference compensation control:

1. Below cut-off frequency, the higher the inductance value, the greater the overshoot of the amplitude-frequency curve; Conversely, the lower the inductance value, the amplitude-frequency curve is closer to unit 1.

2. Below cut-off frequency, the higher the inductance value, the greater the overshoot of the phase-frequency curve; Conversely, the lower the inductance value, the phase-frequency curve is closer to zero.

In conclusion, the smaller the inductance value, the better the effect of reference compensation.

\section{Simulation and Experimental Verification}

To verify the correctness of the theory and the validity of the method, the theoretical derivation was verified under simulation (PSIM) and experiment (laboratory platform). The proposed current control method is applied to active power filter. Parameters are same as list in Table 1.

\subsection{Simulation}

In simulation, a controlled current source is used to inject harmonics into the power grid to simulate the nonlinear load. The harmonic order is 5, 11, 17, 23 and 29 (6n - 1). With optimal virtual resistor, the simulation results are shown in Figure 10. From the simulation results, harmonic component in grid current is very large. By comparing the waveform of reference current and output current, the output current has serious phase lag problem.

The simulation results in Figure 11 are with the reference compensation control. The load does not change, so the load current with reference compensation is just same as Figure 10b. In Figure 11, the load harmonic current is the reference current before compensation (Figure 11b). It is the phase-lag of the reference current after compensation (Figure 11c). Because of the "lowpass filter characteristics" of the inverter, the output current (Figure 11d) is also phase-lag of the reference current after compensation (Figure 11c). That makes the output current (Figure 11c) just in accordance with the load harmonic current (Figure 11b). The harmonic component in grid current is reduced obviously. The control effect of inverter output current is guaranteed.

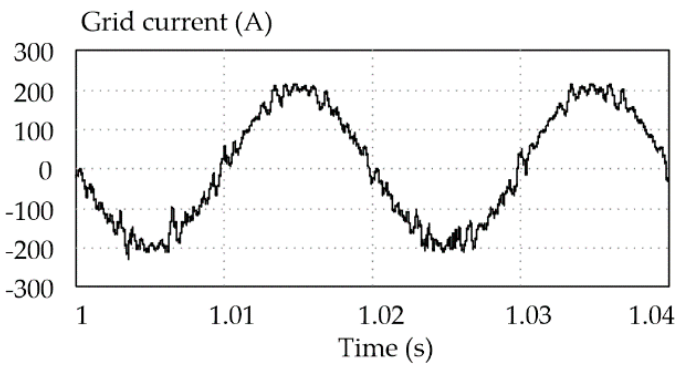

(a)

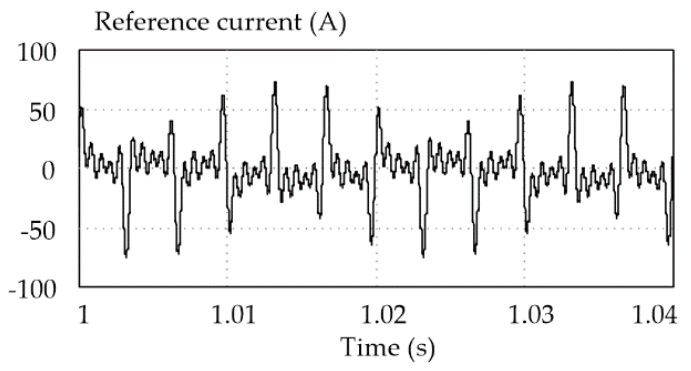

(c)

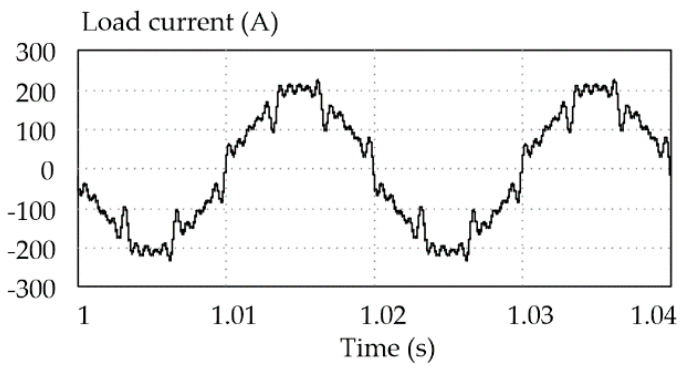

(b)

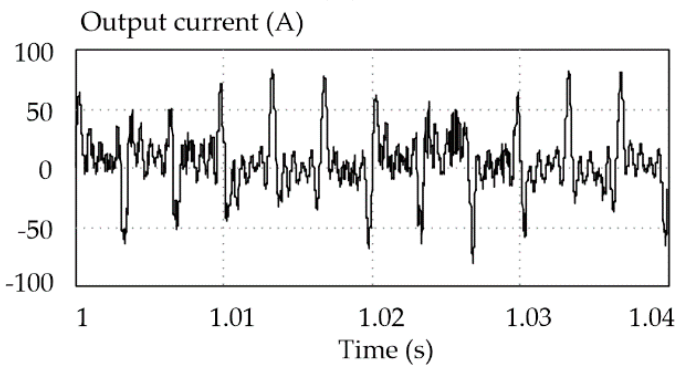

(d)

Figure 10. Simulation result without reference compensation. (a) grid current; (b) load current; (c) reference current; (d) output current. 


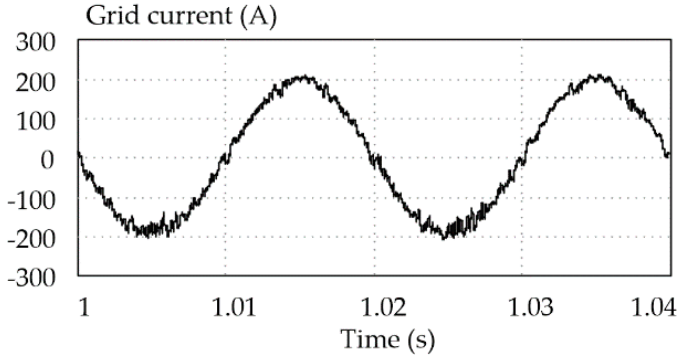

(a)

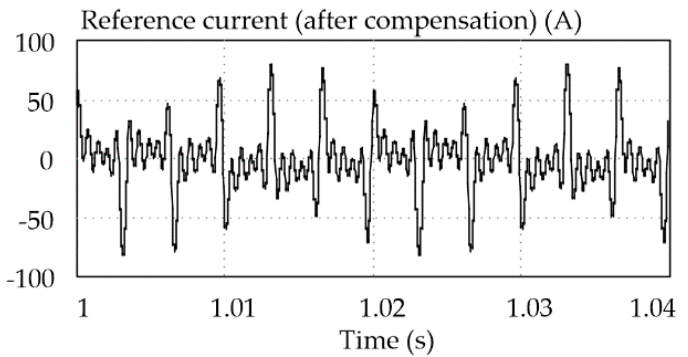

(c)

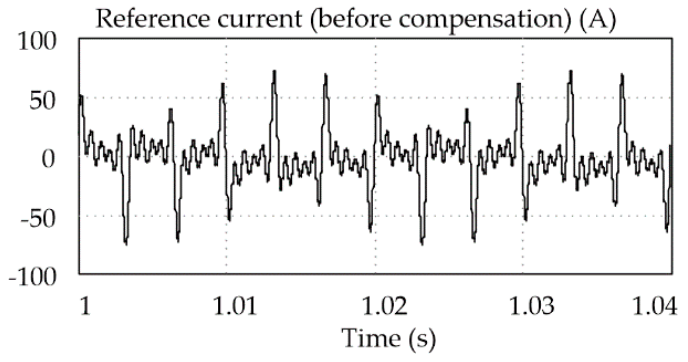

(b)

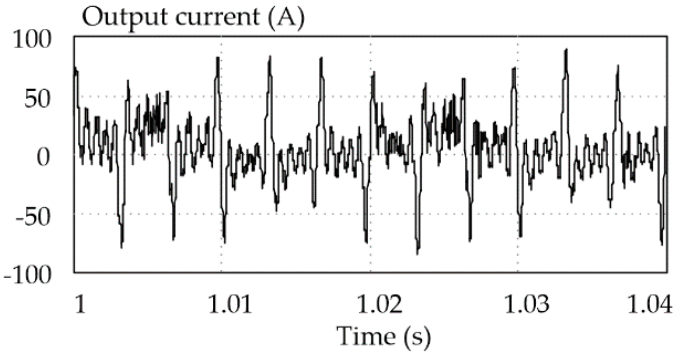

(d)

Figure 11. Simulation result with reference compensation. (a) grid current; (b) reference current (before compensation); (c) reference current (after compensation); (d) output current.

For different LCL parameters (first set of parameters in Table 4), simulation verification is also carried out. The FFT result of the grid current is shown in Figure 12.

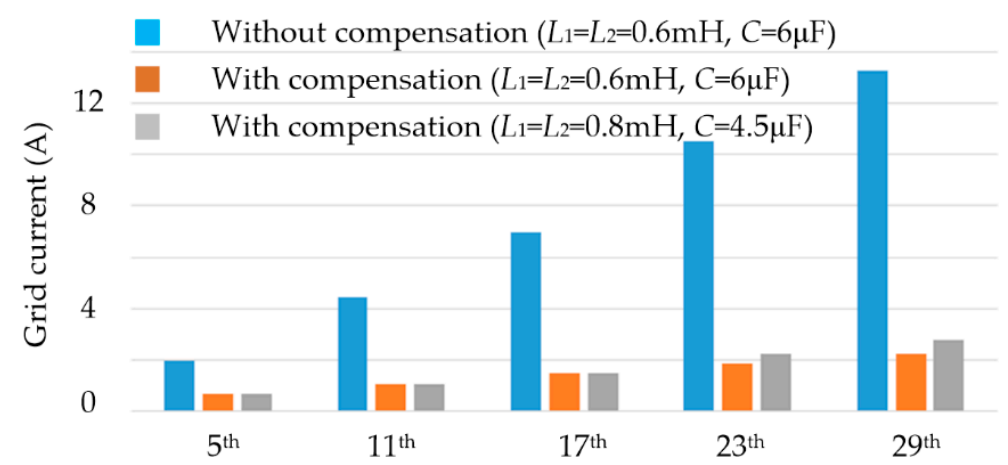

Figure 12. FFT results of grid current.

From Figure 12, when without reference compensation control, the current in power grid contains a large harmonic component, and the harmonic component gradually increases with the increase of frequency. While, with the reference compensation control, the harmonic component in the power grid is obviously smaller, and the improvement effect is still good when the frequency increase. For different LCL parameters, the smaller L value can realize better current control effect.

\subsection{Experiment}

The experimental setup is shown in Figure 13. 


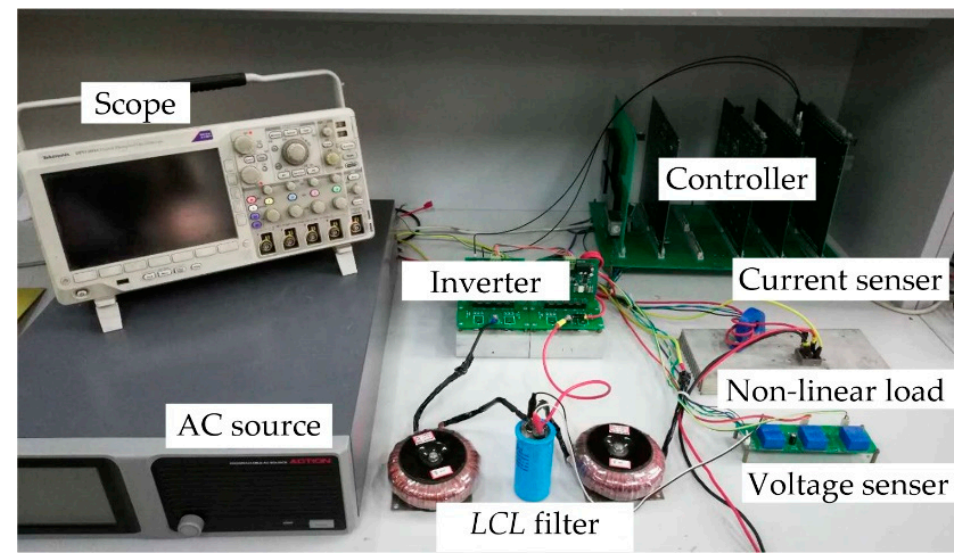

Figure 13. Experimental setup.

The inverter is single-phase $4.5 \mathrm{kVA}$, four discrete insulated-gate bipolar transistors (Infineon IKW40T120) were employed. DSP (Digital Signal Processor, TI TMS320F2812) is the micro-controller, switching frequency and sampling frequency are both $20 \mathrm{kHz}$. The nonlinear load is diode rectifier with resistance-inductance load $\left(R_{\text {load }}=40 \Omega, L_{\text {load }}=2 \mathrm{mH}\right)$.

Figure 14 is the experimental result of grid current, load current and inverter output current. Figure 15 is the FFT analysis of the experimental results.

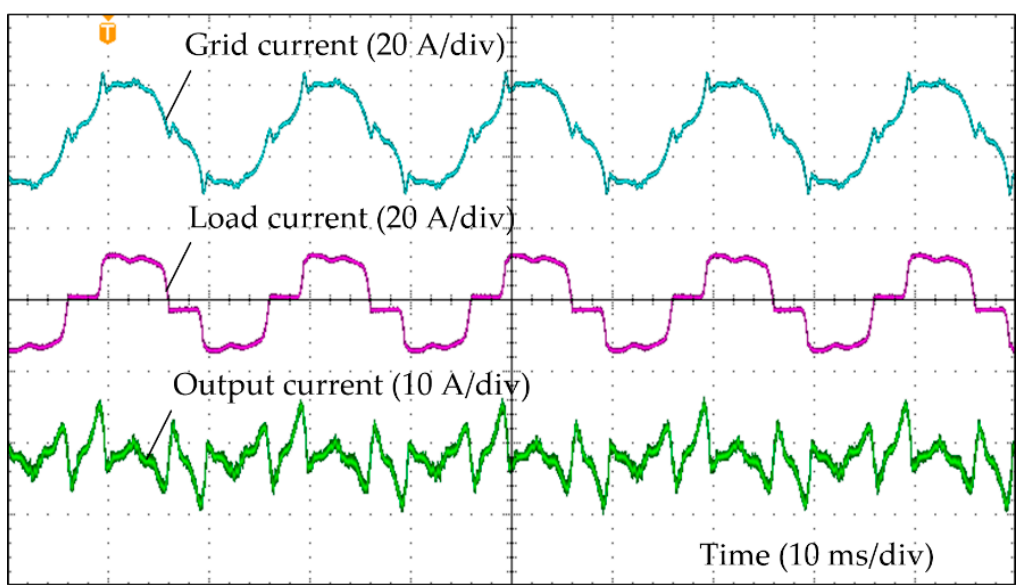

(a)

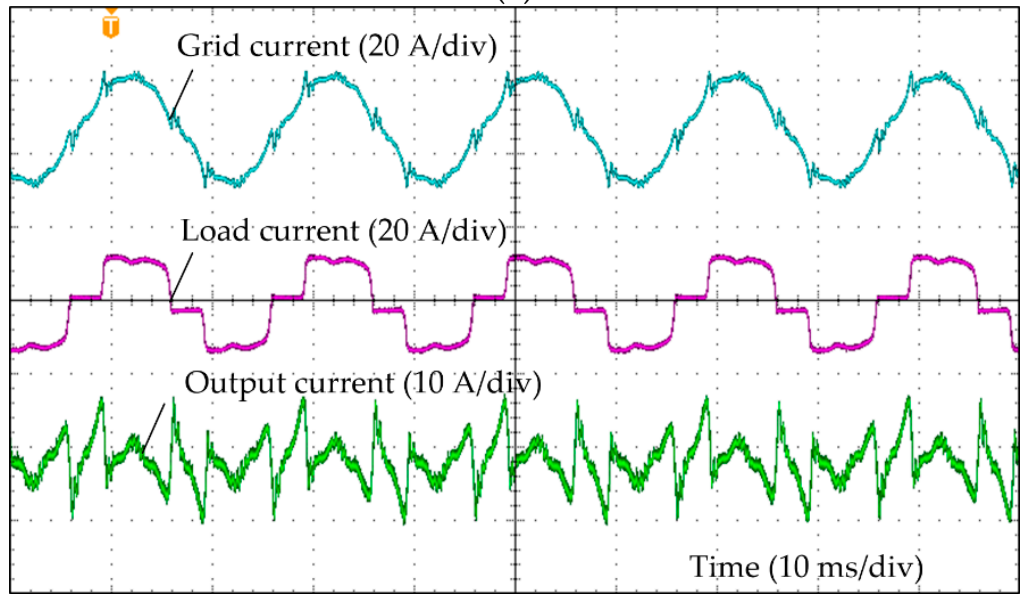

(b)

Figure 14. Experimental result. (a) Without reference compensation; (b) with reference compensation. 
Figure 15a is the amplitude of the inverter output current, and Figure 15b is the phase of the inverter output current. For both control method, the amplitude of the inverter output current is almost the same, means the reference compensation control does not change the amplitude of the output current. But, when without reference compensation, the phase delay problem is serious. And the phase lag angle increases as the frequency increases. With the reference compensation control, the phase delay of output current for each harmonic is compensated well.

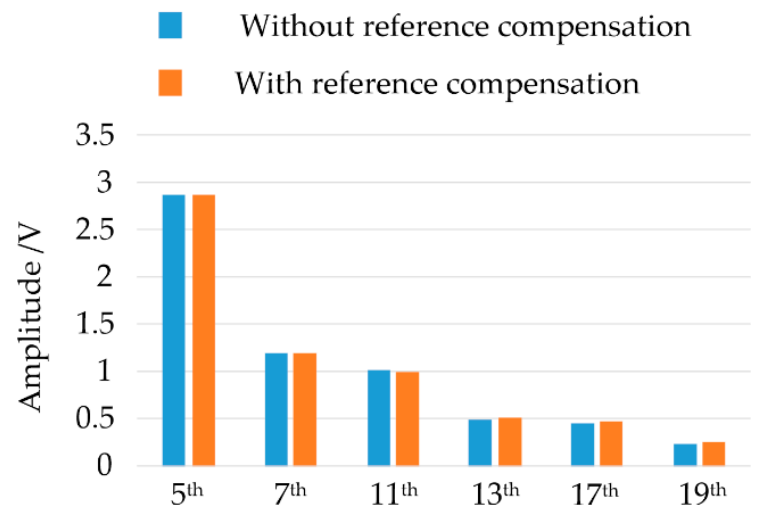

(a)

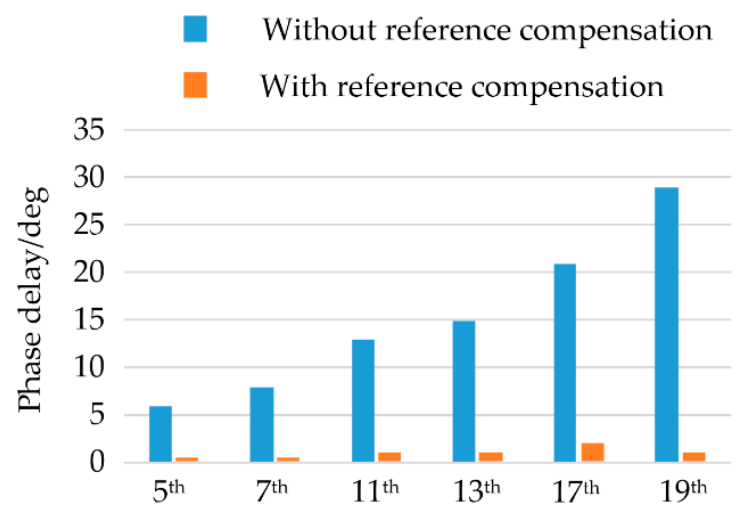

(b)

Figure 15. FFT analysis of Experimental result. (a) Amplitude; (b) phase delay.

\section{Conclusions}

Virtual resistor damping affects the current control character of the inverter. With optimal virtual resistor value, the output current amplitude control precision is enhanced. In this condition, the current source model of the inverter can be simplified as $2^{\text {nd }}$-order lowpass filter. It means the simplified model can also be used to design the reference compensation controller. For the proposed reference compensation method, there is no need to decompose harmonic components, and only requires LCL parameters and current control loop parameters. It greatly simplifies the design of reference compensation.

In this paper, only the steady-state current control effect is analyzed. The study of dynamic characteristics, and typical operations are also very necessary and will be carried out in the next step.

Author Contributions: Conceptualization, C.N. and W.L.; Methodology, C.N. and W.L.; Software, C.N. and S.Y.; Validation, C.N., S.Y. and T.L.; Formal Analysis, C.N. and T.L; Investigation, C.N. and W.L.; Resources, W.L. and Y.W.; Data Curation, C.N. and T.L.; Writing-Original Draft Preparation, C.N.; Writing-Review \& Editing, C.N.; Visualization, C.N.; Supervision, W.L. and Y.W.; Project Administration, W.L.; Funding Acquisition, W.L. and Y.W. All the authors approved the publication.

Funding: This research was funded by National Natural Science Foundation of China, grant number 51207126.

Conflicts of Interest: The authors declare no conflict of interest.

\section{References}

1. Lu, Z.; Li, H.; Qiao, Y. Probabilistic Flexibility Evaluation for Power System Planning Considering Its Association with Renewable Power Curtailment. IEEE Trans. Power Syst. 2018, 33, 3285-3295. [CrossRef]

2. Nejabatkhah, F.; Li, Y.W. Overview of Power Management Strategies of Hybrid AC/DC Microgrid. IEEE Trans. Power Electron. 2015, 30, 7072-7089. [CrossRef]

3. Oureilidis, K.O.; Demoulias, C.S. An enhanced role for an energy storage system in a microgrid with converter-interfaced sources. J. Eng. 2014, 11, 618-625. [CrossRef]

4. Hossain, M.A.; Pota, H.R.; Issa, W.; Hossain, M.J. Overview of AC Microgrid Controls with Inverter-Interfaced Generations. Energies 2017, 10, 1300. [CrossRef]

5. Kallamadi, M.; Sarkar, V. Generalised analytical framework for the stability studies of an AC microgrid. J. Eng. 2016, 6, 171-179. [CrossRef] 
6. Li, Y.; Wu, M.; Li, Z. A Real Options Analysis for Renewable Energy Investment Decisions under China Carbon Trading Market. Energies 2018, 11, 1817. [CrossRef]

7. Agrawal, R.; Jain, S. Multilevel inverter for interfacing renewable energy sources with low $/$ medium- and high-voltage grids. IET Renew. Power Gener. 2017, 11, 1822-1831. [CrossRef]

8. Han, Y.; Li, H.; Shen, P.; Coelho, E.A.; Guerrero, J.M. Review of Active and Reactive Power Sharing Strategies in Hierarchical Controlled Microgrids. IEEE Trans. Power Electron. 2017, 32, 2427-2451. [CrossRef]

9. Chilipi, R.R.; Al Sayari, N.; Beig, A.R.; Al Hosani, K. A Multitasking Control Algorithm for Grid-Connected Inverters in Distributed Generation Applications Using Adaptive Noise Cancellation Filters. IEEE Trans. Energy Convers. 2016, 31, 714-727. [CrossRef]

10. He, J.; Li, Y.W.; Blaabjerg, F.; Wang, X. Active Harmonic Filtering Using Current-Controlled, Grid-Connected DG Units With Closed-Loop Power Control. IEEE Trans. Power Electron. 2014, 29, 642-653. [CrossRef]

11. He, J.; Li, Y.W.; Munir, M.S. A Flexible Harmonic Control Approach through Voltage-Controlled DG-Grid Interfacing Converters. IEEE Trans. Ind. Electron. 2012, 59, 444-455. [CrossRef]

12. Liu, Y.; Lai, C.-M. LCL Filter Design with EMI Noise Consideration for Grid-Connected Inverter. Energies 2018, 11, 1646. [CrossRef]

13. Xu, J.; Xie, S.; Huang, L.; Ji, L. Design of LCL-filter considering the control impact for grid-connected inverter with one current feedback only. IET Power Electron. 2017, 10, 1324-1332. [CrossRef]

14. Hren, A.; Mihalič, F. An Improved SPWM-Based Control with Over-Modulation Strategy of the Third Harmonic Elimination for a Single-Phase Inverter. Energies 2018, 11, 881. [CrossRef]

15. He, J.; Li, Y.W. Hybrid voltage and current control approach for DG grid interfacing converters with LCL filters. IEEE Trans. Ind. Electron. 2013, 60, 1797-1809. [CrossRef]

16. Jalili, K.; Bernet, S. Design of LCL filters of active-front-end two level voltage-source converters. IEEE Trans. Ind. Electron. 2009, 56, 1674-1689. [CrossRef]

17. Tang, Y.; Yao, W.; Loh, P.C.; Blaabjerg, F. Design of LCL Filters with LCL Resonance Frequencies beyond the Nyquist Frequency for Grid-Connected Converters. IEEE J. Emerg. Sel. Top. Power Electron. 2016, 4, 3-14. [CrossRef]

18. Tang, Y.; Loh, P.C.; Wang, P.; Choo, F.H.; Gao, F.; Blaabjerg, F. Generalized design of high performance shunt active power filter with output LCL filter. IEEE Trans. Ind. Electron. 2012, 59, 1443-1452. [CrossRef]

19. Said-Romdhane, M.B.; Naouar, M.W.; Belkhodja, I.S.; Monmasson, E. An Improved LCL Filter Design in Order to Ensure Stability without Damping and Despite Large Grid Impedance Variations. Energies 2017, 10, 336. [CrossRef]

20. Wu, T.F.; Misra, M.; Lin, L.C.; Hsu, C.W. An Improved Resonant Frequency Based Systematic LCL Filter Design Method for Grid-Connected Inverter. IEEE Trans. Ind. Electron. 2017, 64, 6412-6421. [CrossRef]

21. Wu, W.; Liu, Y.; He, Y.; Chung, H.S.; Liserre, M.; Blaabjerg, F. Damping Methods for Resonances Caused by LCL-Filter-Based Current-Controlled Grid-Tied Power Inverters: An Overview. IEEE Trans. Ind. Electron. 2017, 64, 7402-7413. [CrossRef]

22. Tang, Y.; Loh, P.C.; Wang, P.; Choo, F.H.; Gao, F. Exploring Inherent Damping Characteristic of LCL-Filters for Three-Phase Grid-Connected Voltage Source Inverters. IEEE Trans. Power Electron. 2012, 27, 1433-1443. [CrossRef]

23. Liu, F.; Zhou, Y.; Duan, S.; Yin, J.; Liu, B.; Liu, F. Parameter design of a two-current-loop controller used in a grid-connected inverter system with LCL filter. IEEE Trans. Ind. Electron. 2009, 56, 4483-4491. [CrossRef]

24. Lorzadeh, I.; Askarian Abyaneh, H.; Savaghebi, M.; Bakhshai, A.; Guerrero, J.M. Capacitor Current Feedback-Based Active Resonance Damping Strategies for Digitally-Controlled Inductive-Capacitive-Inductive-Filtered Grid-Connected Inverters. Energies 2016, 9, 642. [CrossRef]

25. Jin, W.; Li, Y.; Sun, G.; Bu, L. H $\infty$ Repetitive Control Based on Active Damping with Reduced Computation Delay for LCL-Type Grid-Connected Inverters. Energies 2017, 10, 586. [CrossRef]

26. Yao, W.; Yang, Y.; Zhang, X.; Blaabjerg, F.; Loh, P.C. Design and Analysis of Robust Active Damping for LCL Filters Using Digital Notch Filters. IEEE Trans. Power Electron. 2017, 32, 2360-2375. [CrossRef]

27. Chen, C.; Xiong, J.; Wan, Z.; Lei, J.; Zhang, K. A Time Delay Compensation Method Based on Area Equivalence for Active Damping of an LCL-Type Converter. IEEE Trans. Power Electron. 2017, 32, 762-772. [CrossRef]

28. Pan, D.; Ruan, X.; Wang, X. Direct Realization of Digital Differentiators in Discrete Domain for Active Damping of LCL-Type Grid-Connected Inverter. IEEE Trans. Power Electron. 2018, 33, 8461-8473. [CrossRef] 
29. Zhou, S.; Zou, X.; Zhu, D.; Tong, L.; Kang, Y. Improved Capacitor Voltage Feedforward for Three-Phase LCL-Type Grid-Connected Converter to Suppress Start-Up Inrush Current. Energies 2017, 10, 713. [CrossRef]

30. He, J.; Li, Y.W.; Bosnjak, D.; Harris, B. Investigation and Active Damping of Multiple Resonances in a Parallel-Inverter-Based Microgrid. IEEE Trans. Power Electron. 2013, 28, 234-246. [CrossRef]

31. Nie, C.; Wang, Y.; Lei, W.; Chen, M.; Zhang, Y. An Enhanced Control Strategy for Multiparalleled Grid-Connected Single-Phase Converters with Load Harmonic Current Compensation Capability. IEEE Trans. Ind. Electron. 2018, 65, 5623-5633. [CrossRef]

32. Liu, J.; Miura, Y.; Ise, T. Comparison of Dynamic Characteristics between Virtual Synchronous Generator and Droop Control in Inverter-Based Distributed Generators. IEEE Trans. Power Electron. 2015, 31, 3600-3611. [CrossRef]

33. Xu, H.; Zhang, X.; Liu, F.; Shi, R.; Yu, C.; Cao, R. A Reactive Power Sharing Strategy of VSG Based on Virtual Capacitor Algorithm. IEEE Trans. Ind. Electron. 2017, 64, 7520-7531. [CrossRef]

34. Liu, Z.; Liu, J.; Zhao, Y. A Unified Control Strategy for Three-Phase Inverter in Distributed Generation. IEEE Trans. Power Electron. 2014, 29, 1176-1191. [CrossRef]

(C) 2018 by the authors. Licensee MDPI, Basel, Switzerland. This article is an open access article distributed under the terms and conditions of the Creative Commons Attribution (CC BY) license (http:/ / creativecommons.org/licenses/by/4.0/). 